\title{
RUANG ASIMILASI BUDAYA JEPANG TRADISIONAL DAN MODERN
}

\author{
Meinius Erwin ${ }^{11}$, Alvin Hadiwono ${ }^{2)}$ \\ 1)Program Studi S1 Arsitektur, Fakultas Teknik, Universitas Tarumanagara, meinius.erwin@gmail.com \\ ${ }^{2)}$ Program Studi S1 Arsitektur, Fakultas Teknik, Universitas Tarumanagara, alvinhadiwono@ymail.com
}

\begin{abstract}
Abstrak
Kebudayaan Jepang adalah kebudayaan negara penjajah Indonesia yang paling menonjol dan cukup diminati dibanding dengan negara penjajah Indonesia lainnya seperti Belanda, Inggris, Spanyol, dan Portugis sementara nilai-nilai lokal Indonesia cenderung ditinggalkan karena orang Indonesia lebih cenderung memilih budaya luar dibanding budaya lokal. Sikap Jepang yang mengikuti budaya modern dari barat tanpa meninggalkan budaya asal mereka menjadi contoh untuk Indonesia agar tidak kehilangan nilai-nilai lokalnya sehingga proyek ini bertujuan agar Indonesia tetap dapat menikmati dan mempelajari kebudayaan Jepang tanpa melupakan kebudayaan lokal. Wadah untuk mewujudkan hal tersebut dimulai dari keseharian orang-orang terkait third place. Metode perancangan yang digunakan adalah dengan memanfaatkan kondisi eksisting tapak perancangan sebagai dasar pembentukkan massa bangunan dengan maksud memanfaatkan yang sudah ada seperti yang dipikirkan oleh Louis Isadore Kahn. Edutown BSD menjadi lokasi yang tepat untuk dirancang sebuah proyek yang diusulkan yang berjudul Ruang Asimilasi Budaya Jepang Tradisional dan Modern karena terdapat berbagai bangunan dengan fungsi berbeda-beda seperti pusat perbelanjaan, hiburan, dan pendidikan serta secara kebudayaan terdapat Jepang dan Indonesia; Edutown BSD direncanakan untuk menjadi pusat pendidikan dan riset yang diintegrasikan dengan pusat perbelanjaan, rekreasi, dan kebutuhan lainnya sehingga ikut mendukung perancangan proyek berupa ruang asimilasi. Hasil perancangan berupa bangunan dengan material dan bentuk fisik mengikuti Jepang / modern sementara non fisik lebih kepada budaya Indonesia karena lokalitas tidak hanya sekedar menampilkan wujud fisik saja, sehingga pengertian judul perancangan bukan mencerminkan kebudayaan Jepang secara eksklusif.
\end{abstract}

Kata kunci: asimilasi; budaya; jepang; modern; ruang; tradisional

\begin{abstract}
Japanese culture is a Indonesian colonizer's culture that most stand out and preffered than other Indonesian colonizer's culture like Netherlands, England, Spanish, and Portuguese. In the other hand, the local value of Indonesia preffered to be left out because Indonesian preffered the foreign culture. The Japanese that followed modern western culture without leaving their original culture can be an example for Indonesian not to lose their local values so that this project designed for Indonesian still can consume and learn Japanese Culture without forget their local culture. The space for make that happen starts from the daily life of people related to third place. The design method for this design based on the site existing as a basic for building mass with the purpose of using the existing one like as thought by Louis Isadore Kahn. Edutown BSD is the right location to design a proposed project entitled Japan Cultural Hybrid Space because there are various buildings with different functions like shopping centers, entertainment, and education, and culturally there are Japan and Indonesia; Edutown BSD is planned to be an education and research center that is integrated with shopping centers, recreation, and other needs so that it supports the project design in the form of assimilation space. The design results in the form of buildings with material and physical form follow Japan I modern while non-physical is more on Indonesian culture because locality is not merely displaying physical form, so that the meaning of design title does not reflect Japanese culture exclusively.
\end{abstract}

Keywords: asimilation; culture; japan; modern; space; traditional 


\section{PENDAHULUAN}

Indonesia dihuni oleh penduduk baik dari dalam maupun luar negeri dengan latar belakang suku, ras, agama, dan kebudayaan yang berbeda-beda. Beberapa jenis kebudayaan luar negeri ikut mengisi Indonesia tanpa menghilangkan kearifan lokal budaya Indonesia. Jepang adalah salah satu negara penjajah Indonesia yang saat ini bersahabat baik dengan Indonesia dimulai sejak perjanjian diplomasi Indonesia-Jepang tahun 1958. Kebudayaan dan produk Jepang terlihat paling menonjol dibanding kebudayaan dan produk luar negeri di Indonesia serta cukup diminati dan familiar oleh orang Indonesia seperti penggunaan mobil merk Jepang: Toyota, Daihatsu, Honda, Mitsubishi, dan lainnya yang setiap hari dapat kita lihat di jalan raya, beredarnya restoran-restoran Jepang di Indonesia, hingga festival ala Jepang seperti Ennichisai, Comifuro, dan sejenisnya setiap tahun, demikian pula beberapa makanan khas Indonesia seperti nasi goreng dan rendang juga familiar dan cukup diminati oleh Jepang dan dunia. Jakarta juga memiliki gedung Embassy of Japan dan Japan Foundation yang mendukung informasi dan kegiatan seputar Jepang di Indonesia.

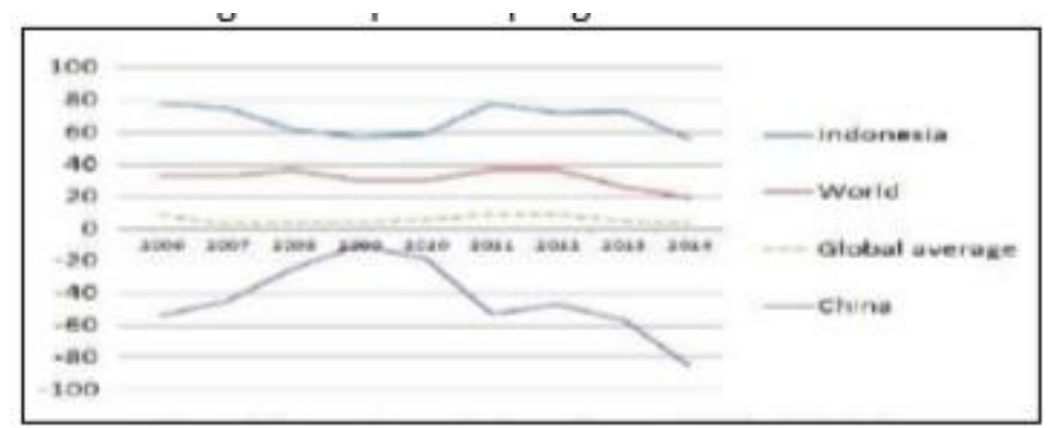

Gambar 1. Respon positif beberapa negara terhadap Jepang tahun $2006-2014$ Sumber: BBC World Service (polls report) dalam jurnal Han, 2015

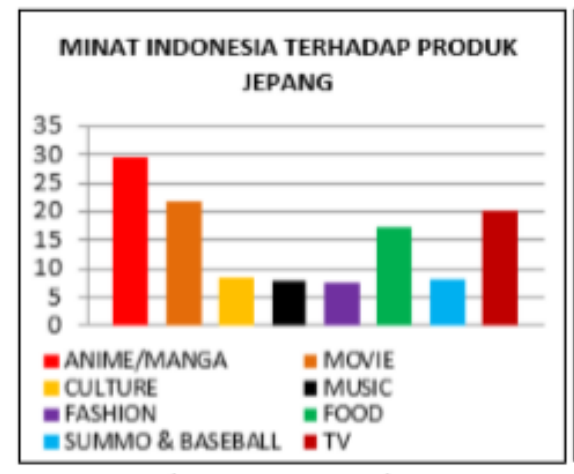

Gambar 2. Minat Indonesia Terhadap beberapa produk Jepang

Sumber: Yomiuri Shimbun dalam jurnal Lam, 2007

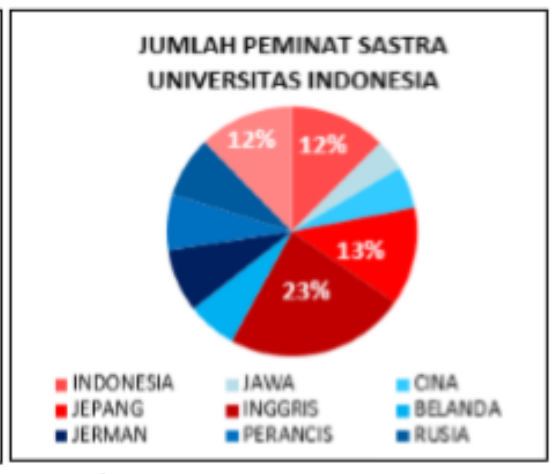

Gambar 3. Minat Sastra Universitas Indonesia Sumber:

https://kampusaja.com/dayatampungpeminat-sbmptn-ui/

Setelah kekalahan Jepang dalam perang dunia ke-2 pada tahun 1945, kerugian Jepang tidak hanya dalam bidang perekonomian dan militer tetapi juga citra negaranya di mata negara lain terutama negara-negara bekas jajahannya. Oleh karena itu Jepang berusaha memperbaiki citra negaranya dengan mengekspos dan menyebarkan kebudayaan yang dimilikinya ke negaranegara lain terutama Indonesia dengan cara diplomasi, yaitu penyebaran bahasa dan kebudayaan Jepang hingga saat ini termasuk juga teknologi dan nilai sikap yang dapat dicontoh oleh orang Indonesia, demikian juga Indonesia dengan jumlah penduduk yang sangat padat dapat menjadi tenaga kerja bagi Jepang yang semakin hari semakin berkurang populasinya akibat perkembangan teknologi dan kurang keinginan untuk meneruskan keturunan. Saat ini 
nilai lokal Indonesia cenderung menurun; orang Indonesia lebih cenderung mengonsumsi produk dan kebudayaan luar negeri daripada Indonesia meskipun tidak ditinggalkan secara menyeluruh, salah satunya adalah data mengenai volume impor di Indonesia menurut Supply Chain Indonesia (2019) seperti pada gambar 4, padahal kebudayaan Indonesia sangat diminati dan diakui oleh negara lain terutama Jepang. Selain kemajuan teknologi Jepang dan keunggulan produk-produknya yang dapat dinikmati dan dicontoh oleh Indonesia, Jepang memiliki cara tersendiri dalam menyikapi kebudayaan yang mereka miliki. Kebudayaan Jepang yang kita kenal saat ini merupakan perpaduan kebudayaan mereka sendiri yang populer sejak periode Edo dan kebudayaan orang barat yang memajukan kebudayaan lokal mereka sehingga Indonesia juga dapat mencontoh Jepang dalam hal menerima budaya luar tanpa meninggalkan budaya lokal.

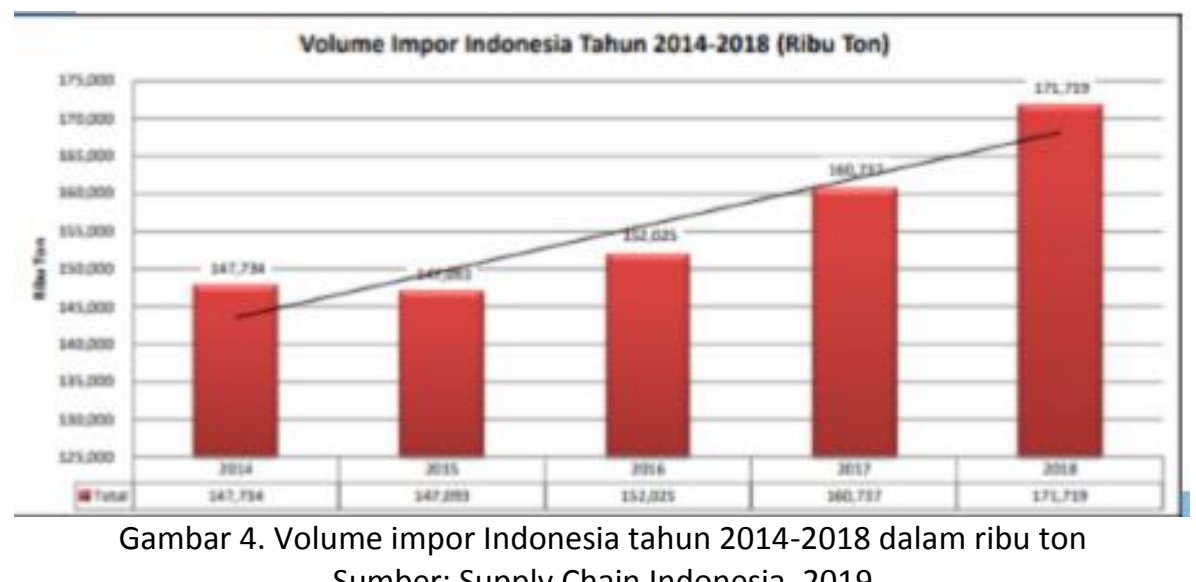

Sumber: Supply Chain Indonesia, 2019

Agar hal tersebut terwujud dengan lebih mudah tentunya dimulai dari kebiasaan dan keseharian orang-orang di mana terdapat first place (tempat tinggal), second place (tempat bekerja), dan third place (umumnya sebagai ruang pemulihan kejenuhan dari first place dan second place). Melihat first place dan second place yang cenderung konstan dan dilakukan terusmenerus, third place berpotensi untuk menyelesaikan masalah tersebut di mana orang Indonesia yang umumnya keluar dari nilai lokalnya diajak untuk kembali ke nilai lokalnya tanpa harus menghilangkan budaya luar tersebut.

Dalam melakukan sebuah perancangan untuk masalah tersebut, penulis mengawali perancangan dengan beberapa pertanyaan awal, yaitu: 1 . Bagaimana Indonesia menerima budaya luar sekaligus mempertahankan budaya lokal seperti yang dilakukan oleh Jepang? 2 . Bagaimana keterkaitan rancangan proyek dengan third place? Perancangan bertujuan mempengaruhi orang Indonesia agar tidak menghilangkan nilai lokalnya ketika menikmati budaya luar dan kesamarataan antara budaya Indonesia dengan budaya luar terutama Jepang. Isu perancangan dibatasi dengan skala kelurahan agar hasil perancangan terlampaui mengingat keterbatasan waktu perancangan, yaitu lima bulan.

\section{KAJIAN LITERATUR}

\section{Third Place}

Istilah third place berawal dari sebuah bentuk protes terhadap jenis perumahan automobile suburb di Amerika, yaitu pemisahan tempat tinggal, bekerja, dan keperluan lainnya. Jenis perumahan tersebut mudah ditinggalkan karena tidak dapat memenuhi kebutuhan di luar tempat tinggal dan bekerja yang bersifat informal untuk kepuasan hidup dan sosial. Faktor utama yang menyebabkannya adalah rasa bosan, stres, kesendirian, pengasingan, dan biaya hidup tinggi, juga oleh penjagaan diri yang terlalu ketat sehingga tidak memunculkan kontak antar sesama. Solusi yang dipandang baik untuk menyelesaikan masalah tersebut adalah 
dengan memperkaya fasilitas third place yang pada masa itu semakin lama semakin menghilang. Third place memiliki karakteristik seperti berikut.

a. Netral, leveller, dan percakapan

- Kondisi netral menciptakan sebuah tempat (place) di mana orang-orang dalam kebebasannya memilih untuk mendatanginya, kemudian leveller membentuk aktivitas dari perkumpulan orang-orang tersebut, yaitu percakapan (conversation) sebagai aktivitas utamanya.

- Netral : setiap orang dapat mengunjungi third place sesuka hati tanpa harus ada seseorang yang menjadi tuan rumah atas tempat tersebut (status sosial abstrak; tidak ada kesungkanan untuk berbicara seperti pada atasan dan bawahan) yang menciptakan perkumpulan social yang bevariasi sesuai potensial masing-masing orang

- Leveler : Inklusif, tidak ada kriteria yang sangat formal bagi orang-orang tersebut, sehingga lebih tercipta kenikmatan berinteraksi dengan orang lain dan lebih terbuka (bebas memilih teman) daripada dalam lingkungan kerja

- Conversation : Percakapan menyangkut interaksi dan aktivitas-aktivitas dalam tempat netral tersebut, tidak hanya dengan mulut tetapi juga dengan hal-hal fisik seperti senyuman, kedipan mata, berjabat tangan, dan sejenisnya. Orang cenderung bersosialisasi daripada minum; orang-orang lebih menikmati sosialisasi daripada produk yang dibeli dalam pub tersebut. (pengamatan oleh Tibor Scitovsky pada beberapa English pub)

b. Aksesibilitas dan akomodasi

- Frekuensi pengunjungan third place secara teratur tetapi tidak selalu tepat waktu: ada ketidakkonsistenan seperti melewatkan beberapa hari, waktu kunjungan yang renggang, atau waktu kunjungan yang singkat.

- Aktivitas-aktivitas tidak direncanakan, dijadwalkan, dikelola, dan terstruktur.

- Mudah dikunjungi seperti contoh terletak dekat rumah sehingga sering dikunjungi dan para pelanggannya ditemani oleh wajah-wajah akrab yang merupakan orang-orang di daerah perumahan tersebut.

c. Identitas lokal (Memiliki pelanggan tetap atau regular) Karakteristik pelanggan tetap third Place lebih menarik dibandingkan dengan bagaimana pengelolaan third place tersebut. Daya tarik Third Place adalah fitur-fitur tertentu seperti contohnya ketersediaan parkir, makanan atau minuman (menu), harga, dan sejenisnya.

d. Low profile Tidak ada kepura-puraan (plainness); setiap pelanggan datang dengan keadaan sebagaimana mereka ada, tidak seperti berdandan di rumah terlebih dahulu seperti menghadiri sebuah pesta atau acara formal.

\section{e. Playful}

f. A home away from home

Third place terasa seperti rumah tetapi tidak seperti layaknya rumah dan tidak dapat menggantikan sebuah rumah. Persamaannya dengan rumah adalah pelanggan melihat wajahwajah sesamanya yang familiar dan saling memperhatikan sesamanya. Perbedaannya adalah tidak memiliki keteraturan penampilan yang baku dan tidak memiliki hirarki; semua orang dalam kedudukan yang sama, contoh: orang dengan jenis kelamin sama, dan tidak ada rasa sungkan seperti mengunjungi rumah orang lain.

\section{Kebudayaan Jepang}

Kebudayaan secara sempit diartikan sebagai kesenian, sastra, musik, dan lukisan seperti halnya seniman yang dianggap sebagai budayawan. Secara luas, kebudayaan adalah keseluruhan cara hidup anggota-anggota masyarakat: cara berpakaian, adat kebiasaan perkawinan, pola kerja, upacara keagamaan, pencarian kesenangan, dan barang-barang yang diciptakan yang juga 
bermakna bagi pembuatnya. Kebudayaan tradisional Jepang sangat dekat dengan alam berdasarkan konsep agama Shinto yang percaya akan dewa-dewa yang hadir dalam setiap unsur alam (batu, gunung, pohon, air terjun, dll) sehingga menghasilkan sifat menghargai alam. Kekayaan budaya Jepang tampil paling menonjol dalam periode Edo. Untuk modernisasi, Jepang juga mengadaptasi budaya barat tanpa kehilangan nilai-nilai lokal mereka; mereka justru dapat menggabungkan keduanya menjadi budaya Jepang yang dapat kita lihat saat ini, seperti contohnya adalah Nakagin Capsule Hotel yang menggunakan material modern seperti beton dengan konsep beberapa point kebudayaan Jepang seperti bento box, ruang minum teh, dan juga konsep modern seperti astronot. Karakteristik kebudayaan Jepang seperti zen dan pemikiran orang Jepang (Japanese mind) juga berkaitan dengan karakteristik third place.

Tabel 1. Hubungan karakteristik Third Place dan karakter budaya Jepang

\begin{tabular}{|c|c|c|}
\hline ZEN & THIRD PLACE & $\begin{array}{c}\text { JAPANESE MIND \& } \\
\text { BEHAVIOR }\end{array}$ \\
\hline \multirow{2}{*}{$\begin{array}{l}\text { Asimetris (Fukunsei) } \\
\text { Ketidakteraturan seperti } \\
\text { lingkaran miring, angka } \\
\text { ganjil }\end{array}$} & \multirow{2}{*}{$\begin{array}{l}\text { Permeabilitas } \\
\text { Tidak terikat pada suatu } \\
\text { aturan kaku atau pasti; } \\
\text { ada ketidakkonsistenan. } \\
\end{array}$} & $\begin{array}{l}\text { Ambiguity } \\
\text { Satu kata dapat didefinisikan } \\
\text { menjadi berbagai macam arti }\end{array}$ \\
\hline & & \multirow{2}{*}{$\begin{array}{l}\text { Wabi sabi } \\
\text { Emptyness; suatu keindahan } \\
\text { yang terdapat dalam pikiran } \\
\text { seperti sedikitnya ornamen } \\
\text { bangunan sehingga setiap } \\
\text { orang dapat mendefinisikan } \\
\text { "ornamen"nya sendiri dalam } \\
\text { pikirannya. } \\
\end{array}$} \\
\hline $\begin{array}{l}\text { Bebas dari ikatan } \\
\text { (datsuzoku) } \\
\text { Bebas dari aturan, } \\
\text { kebiasaan, rumus, dan } \\
\text { sejenisnya }\end{array}$ & $\begin{array}{l}\text { Equality } \\
\text { Tidak ada kriteria formal } \\
\text { atau kaku bagi } \\
\text { pengunjungnya }\end{array}$ & \\
\hline $\begin{array}{l}\text { Kealamian (shizen) } \\
\text { Menjadi diri yang } \\
\text { sesungguhnya } \\
\text { dibuat-buat. }\end{array}$ & $\begin{array}{l}\text { A low profile } \\
\text { tampil apa adanya tidak } \\
\text { seperti berdandan dahulu } \\
\text { sebelum berpesta }\end{array}$ & 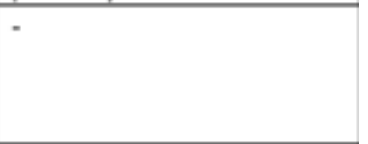 \\
\hline \multirow{2}{*}{$\begin{array}{l}\text { Kesederhanaan (kanso) } \\
\text { Mencerminkan sifat suatu } \\
\text { benda secara utuh, tidak } \\
\text { kacau dan bercampur } \\
\text { aduk. }\end{array}$} & \multirow{3}{*}{$\begin{array}{l}\text { Netral } \\
\text { Semua orang sama, } \\
\text { status sosial tiap orang } \\
\text { sama tidak ada yang lebih } \\
\text { tinggi atau menonjol. }\end{array}$} & $\begin{array}{l}\text { Kesederhanaan } \\
\text { Kesenangan besar dalam } \\
\text { melakukan hal-hal sederhana } \\
\text { seperti makan, minum, dll. }\end{array}$ \\
\hline & & \multirow{2}{*}{$\begin{array}{l}\text { Silence } \\
\text { Tidak mengekpresikan } \\
\text { keseluruhan pikiran untuk } \\
\text { menghindari konflik atau } \\
\text { status yang lebih tinggi. }\end{array}$} \\
\hline $\begin{array}{l}\text { Ketenangan (seijaku) } \\
\text { tidak terganggu; diam } \\
\text { tetapi memiliki bentuk } \\
\text { bergerak. }\end{array}$ & & \\
\hline $\begin{array}{l}\text { Kekeringan yang agung } \\
\text { (kokou) } \\
\text { Sesuatu memiliki nilai } \\
\text { lebih apabila sudah } \\
\text { ada/hidup lebih lama }\end{array}$ & \multirow{2}{*}{$\begin{array}{l}\text { Local identity } \\
\text { Identitas lokal semakin } \\
\text { hidup bila pengalamannya } \\
\text { semakin lama }\end{array}$} & - \\
\hline $\begin{array}{l}\text { Kedalaman } \\
\text { (Yuugen) } \\
\text { Makna yang mendalam; } \\
\text { sesuatu yang tidak } \\
\text { berdasar dan tidak } \\
\text { berakhir. }\end{array}$ & & - \\
\hline & \multirow[t]{2}{*}{$\begin{array}{l}\text { Conversation } \\
\text { Percakapan menjadi } \\
\text { aktivitas utama }\end{array}$} & $\begin{array}{l}\text { Personal Space } \\
\text { Terdapat dua jenis } \\
\text { hubungan: Hedatoru dan } \\
\text { nojimu. Interaksi (najimu) } \\
\text { umumnya dibangun dengan } \\
\text { memberikan sesuatu (gift) } \\
\text { atau beberapa orang } \\
\text { ditempatkan bersama dalam } \\
\text { kondisi tertentu seperti } \\
\text { festival honami. }\end{array}$ \\
\hline & & $\begin{array}{l}\text { Komunalitas } \\
\text { Keberadaan atau identitas } \\
\text { seseorang lebih muncul } \\
\text { dalam kelompok dibanding } \\
\text { individu }\end{array}$ \\
\hline
\end{tabular}

Sumber: Studi literature oleh Penulis, 2019 
Lokalitas Lokalitas memiliki sebuah sentuhan personal seperti perasaan di rumah dalam sebuah lingkungan serta mengerti dan memahami arsitektur dari sejarah masa lampau sehingga tidak hanya membuat imitasi arsitekturnya saja. Lokalitas bertujuan memenuhi kebutuhan manusia yang dalam perkembangannya memanfaatkan teknologi yang berkelanjutan. Lokalitas dan global pada hakikatnya saling melengkapi.

Hybridity Dalam mencampurkan atau membaurkan dua objek, dalam hal ini adalah kebudayaan, hakikatnya adalah satu objek yang berperan sebagai yang memerintah (ruler) dan yang diperintah (ruled). Hal tersebut memang menimbulkan suatu jarak atau pemisah tetapi dapat juga menciptakan sebuah ruang tengah yang juga disebut third space atau in-between space yang di dalamnya dapat terjadi interaksi berupa pertemuan, negosiasi, atau konflik dengan tujuan utama menciptakan equality di antara kedua kebudayaan tersebut.

\section{METODE}

\section{Metode pra-rancang}

Proses perancangan diawali dengan beberapa tahap berikut.

a. Studi literatur dilakukan sebagai langkah awal untuk memahami gambaran umum proyek yang akan dirancang, dilakukan dalam tahap-tahap berikut.

- Mempelajari definisi, latar belakang, dan karakteristik third place.

- Memilih isu yang akan diangkat terkait third place, dalam hal ini kebudayaan Jepang.

- Mempelajari kebudayaan secara umum dan spesifik (Jepang) terutama karakteristik kebudayaan yang menjadi latar belakang terbentuknya suatu produk terkait karakteristik third place sehingga inspirasi berdasarkan suatu produk bukan sematamata karena imitasi.

b. Menentukan lokasi yang sesuai dengan isu terpilih.

c. Survey, dilakukan dengan mengunjungi langsung tapak terpilih untuk mendapatkan gambaran nyata mengenai keadaan fisik tapak. Survey juga dilakukan kepada warga di sekitar tapak perancangan dengan wawancara langsung dan penyebaran kuesioner kepada dua puluh warga yang tinggal atau berkeperluan di BSD untuk mengidentifikasi fenomena apa saja yang menonjol terhadap kebudayaan Jepang dari segi minat, kebutuhan, kendala, dan lainnya.

d. Menentukan program berdasarkan jawaban responden dan kondisi lingkungan di sekitar lokasi perancangan dalam proyek. e. Membuat konsep perancangan, meliputi ide-ide dasar yang akan digunakan dalam proses perancangan, termasuk transformasi karakteristik kebudayaan Jepang ke dalam bentuk fisik / nyata (desain)

\section{Metode Perancangan}

Perancangan (wujud fisik bangunan) menggunakan metode yang dipikirkan oleh Louis Isadore Kahn yang memanfaatkan kondisi eksisting yang sudah ada; mengembangkan desain dengan membiarkannya menjadi seperti yang diinginkan oleh benda atau objek tersebut seperti yang dijelaskan dalam buku Heidegger for Architects oleh Adam Sharr. (Adam Sharr, 2007: 98). Dalam perancangan ini, kondisi eksisting berupa wujud fisik tapak berupa rerumputan yang terpangkas membentuk suatu pola akibat sering dilalui pengendara motor untuk jalan pintas. Pola tersebut menjadi dasar terbentuknya massa bangunan. 


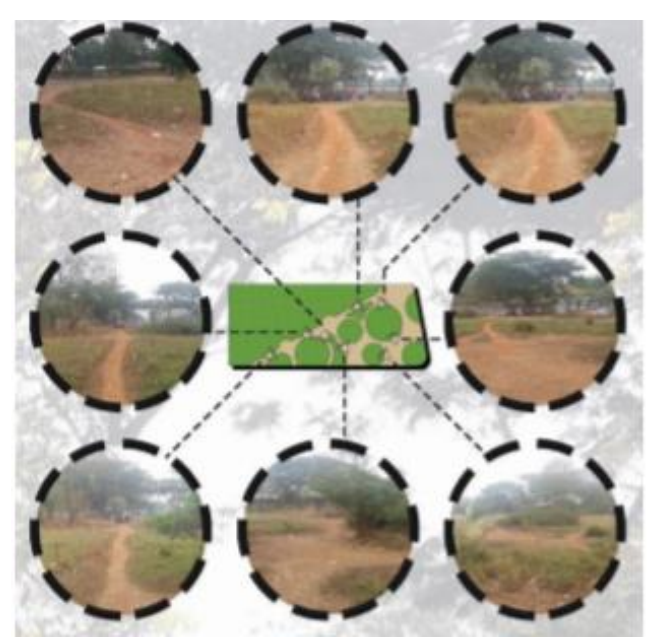

Gambar 5. Kondisi eksisting tapak Sumber: Dokumentasi penulis, 2019

\section{DISKUSI DAN HASIL}

\section{Tinjauan Lokasi}

Tapak perancangan berada di Edutown BSD, Jalan BSD Raya Utama, kelurahan Pagedangan, Kecamatan Pagedangan, tepatnya di seberang AEON Mall BSD sebelah barat. Secara fisik, tapak tersebut berada di antara dua jenis karakter lokasi: sebelah timur tapak berkarakter budaya Jepang seperti AEON Mall dan apartment BRANZ BSD, sebelah barat tapak berkarakter budaya Indonesia dan pendidikan seperti Universitas Prasetya Mulya dan ITSB beserta kumpulan para ojek online dan para pedagang kaki lima yang menjual gorengan, cilok, dan minuman. Secara perencanaan ke depan, Edutown merupakan kawasan milik BSD yang akan dikembangkan sebagai pusat riset dan pendidikan yang diintegrasikan dengan pusat perbelanjaan, tempat tinggal, rekreasi, dan kebutuhan lainnya. Kondisi fisik dan perencanaan lokasi demikian memungkinkan dirancanganya sebuah ruang asimilasi yang mempertemukan seluruh kondisi tersebut: asimilasi antara budaya Jepang dengan Indonesia dan belajar dengan bermain.

Akses menuju tapak tersebut didominasi oleh jalan raya untuk kendaraan bermotor dan bus BSD link, juga dilengkapi trotoar yang dapat dipakai oleh pejalan kaki dan sepeda. Warga sekitar BSD masih banyak yang menggunakan mobil dan motor sehingga aksesibilitas tapak cukup mudah meskipun tidak semua pengunjung tinggal di dekat daerah Edutown BSD.

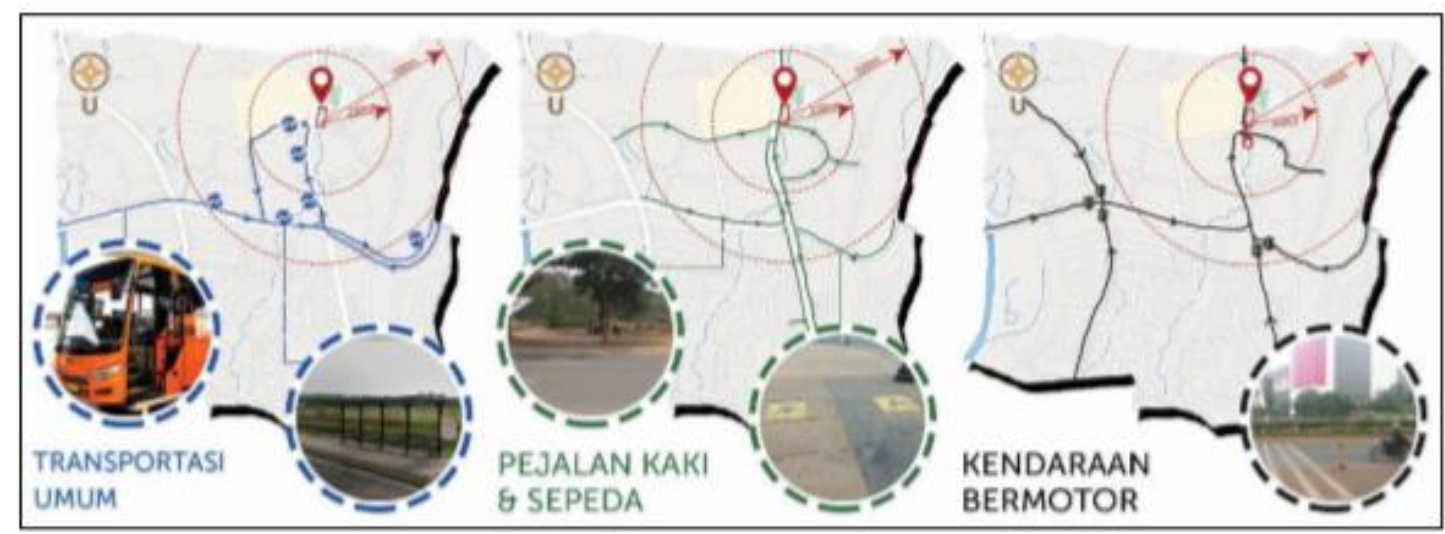

Gambar 6. Akses menuju tapak perancangan

Sumber: Dokumentasi penulis, 2019

\section{Tinjauan Aktivitas}

Third Place dimulai dari keseharian orang-orang sehingga program dalam perancangan berangkat dari aktivitas-aktivitas sekitar tapak. Aktivitas sekitar tapak ditinjau dari AEON mall 
BSD, Universitas Prasetya Mulya, apartment BRANZ BSD, pedagang kaki lima, ojek online. AEON Mall diutamakan untuk menjadi Food Culture, tetapi juga menjadi tempat diadakannya kegiatan-kegiatan festival kebudayaan Jepang. Mall ini sering dikunjungi oleh kalangan dewasa dan anak kecil, yaitu orang tua yang jalan-jalan bersama anak-anaknya. Meskipun tidak setiap hari pergi ke mall, tetap banyak pengunjung di setiap harinya. Food Culture yang dimaksud adalah kumpulan makanan Jepang yang terkenal seperti ramen dan sushi tetapi juga makananmakanan dari negara lain seperti Indonesia, Korea, dan barat berupa food court dan kios-kios makanan, dilengkapi juga dengan supermarket yang menjual kebutuhan sehari-hari. Selain Food Culture terdapat juga fasilitas lainnya yang tidak kalah ramai seperti: Kidzoona (tempat main anak-anak), sakura park (umumnya dikunjungi ketika malam hari untuk jalanjalan, foto-foto atau selfie, nongkrong, dan terkadang bersepeda), dan magic fountain.

Apartment BRANZ, apartment dengan gaya Jepang dihuni 50\% dari keseluruhan unitnya selebihnya untuk investasi. Apartment tersebut dilengkapi dengan ruang serbaguna ini yang setiap bulan diadakan acara kebudayaan Jepang seperti memasak makanan ala Jepang (umumnya) dan lainnya.

Universitas Prasetya Mulya memiliki mahasiswa yang umumnya mengerjakan tugas mata kuliah di kampus, baik di kelas maupun di kantin sambil makan. Mencari hiburan atau hal lainnya di luar mata kuliah ketika meninggalkan kampus, umumnya ke AEON mall untuk makan atau nonton. Terdapat juga ITSB yang yang masih dalam proses pembangunan.

Terdapat banyak pedagang kaki lima di sekitar depan Universitas Prasetya Mulya, pinggir jalan menuju daerah kost, dan sedikit di tapak perancangan. Para pedagang tersebut menjual makanan khas Indonesia seperti cilok dan gorengan lainnya di daerah-daerah tersebut. Pelanggan mereka adalah para ojek yang sedang singgah atau nongkrong untuk waktu istirahat di tengah kesibukannya dan mahasiswa kampus. Kumpulan ojek terbanyak terdapat di tapak perancangan.

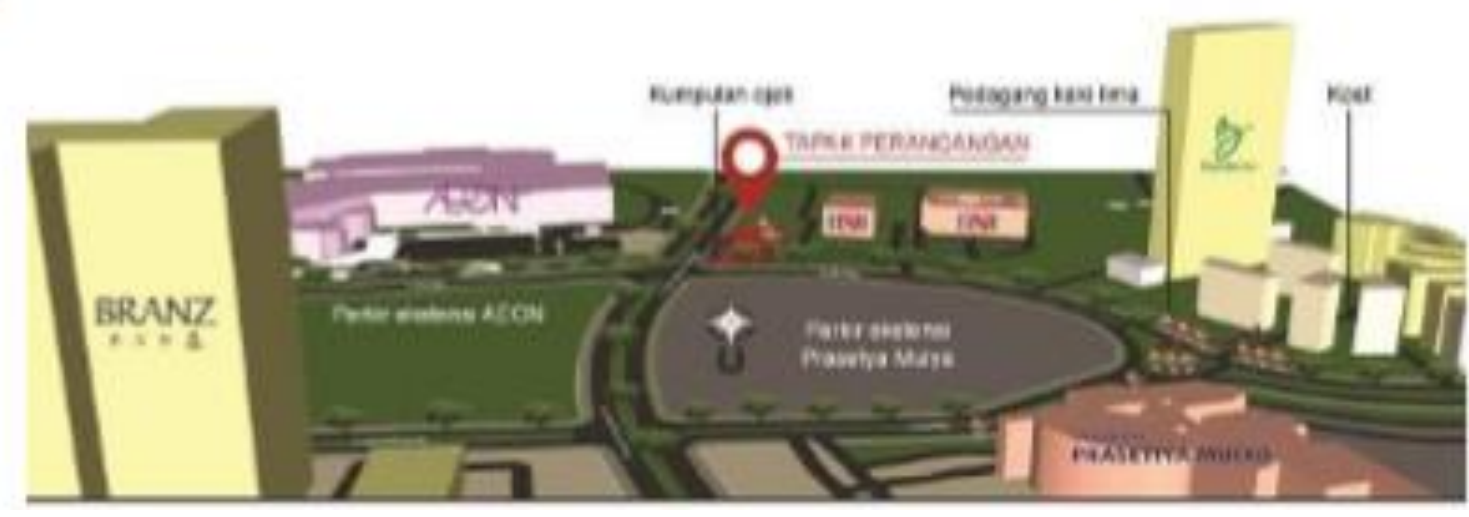

Gambar 7. Kondisi fisik lingkungan tapak perencanaan Sumber: Dokumentasi penulis, 2019

\section{Konsep perancangan}

Seperti halnya Jepang mengadaptasi budaya modern tanpa menghilangkan nilai lokal mereka, demikian pula Indonesia mengadaptasi budaya Jepang tanpa menghilangkan budaya lokal Indonesia, sehingga pengertian judul perancangan bukan mencerminkan kebudayaan Jepang secara eksklusif tetapi lebih kepada bagaimana Indonesia mencoba menerapkan cara Jepang dalam mengadaptasi budaya luar tanpa menghilangkan nilai lokal demi kemajuan dan promosi budaya; diwujudkan dalam sebuah ruang asimilasi budaya yang tidak eksklusif pada budaya masing-masing.

Mengikuti konsep lokalitas, material dan bentuk fisik mengikuti budaya luar / modern sementara non fisik lebih kepada budaya asal karena lokalitas tidak hanya sekedar menampilkan wujud fisik saja. Cara tersebut sudah pernah dilakukan oleh Jepang seperti contohnya pada Nakagin Capsule Hotel. 
Tabel 2. Perbandingan Jepang dan Indonesia (perancangan) dalam perancangan bangunan

\begin{tabular}{l|l|l}
\multicolumn{1}{c|}{ KONTEN } & \multicolumn{1}{|c}{ JEPANG } & \multicolumn{1}{c}{ INDONESIA } \\
\hline $\begin{array}{l}\text { Nilai lokal/budaya } \\
\text { asal }\end{array}$ & Jepang (Edo) & Indonesia (nusantara) \\
\hline $\begin{array}{l}\text { Budaya luar / pemicu } \\
\text { modernisasi }\end{array}$ & Negara barat (modern) & Jepang tradisional dan modern \\
\hline Wujud fisik & $\begin{array}{l}\text { Material modern (beton, baja, } \\
\text { kaca) }\end{array}$ & $\begin{array}{l}\text { Bentuk fisik kebudayaan Jepang } \\
\text { seperti: material dan modul } \\
\text { tatami, kios makanan Jepang, pola } \\
\text { grid. }\end{array}$ \\
\hline $\begin{array}{l}\text { Wujud non fisik / } \\
\text { karakter }\end{array}$ & $\begin{array}{l}\text { Nilai-nilai tradisional Jepang } \\
\text { (Zen dan Japanese mind) }\end{array}$ & $\begin{array}{l}\text { Budaya sehari-hari orang } \\
\text { Indonesia seperti: nongkrong, } \\
\text { duduk lesehan, bersantai. }\end{array}$ \\
\hline
\end{tabular}

Sumber: Studi literatur dan tinjauan lokasi perancangan oleh penulis, 2019

\section{Program perancangan}

Berdasarkan isu umum yakni budaya Jepang yang banyak diminati, survey kepada dua puluh warga BSD, dan aktivitas di sekitar tapak perancangan, program utama adalah tentang makanan yang secara eksisting paling menonjol, kemudian transportasi, hingga anime/manga; diurutkan dari paling inklusif sampai ekslusif. Program makanan berupa tempat makan yang dapat diakses pengunjung secara bebas, terdiri dari program-program seperti berikut.

1. Bar, dalam artian tempat duduk linear, pengunjung langsung berhadapan dengan penjual yang memasak makanan tepat di depan pengunjung seperti pada kios-kios tradisional Jepang dan kaki lima Indonesia.

2. Group tersedia seperti biasa dengan kursi dan meja seperti foodcourt pada umumnya yang jauh dari pelayan yang membuat makanan, juga lesehan dengan material tatami yang kosong tanpa perabot sehingga dapat digunakan scara bebas dan berbagai pilihan; tersedia juga kursi kecil, meja kecil, dan bantal yang dapat digunakan pada lesehan tatami sesuai selera dan keinginan masing-masing, dapat digunakan sesuai selera Jepang dengan meja kecil dan bantal, sesuai selera Indonesia lesehan tanpa perabot, ataupun bentuk selera lainnya. Karena terletak di kawasan edutown, tersedia juga tempat galeri bahan makanan yang dapat diambil oleh pengunjung untuk dimasak dan tersedia juga dapur publik yang dapat digunakan untuk membuat makanan dan minuman secara bebas sehingga pengunjung selain dapat menikmati jenis makanan juga dapat sambil belajar membuat makanan dan minuman atau berkreasi membuat makanan secara bebas; kegiatan membuat makanan/minuman dapat dilakukan sendiri atau dibuatkan oleh pelayan seperti restoran pada umumnya.

3. Budidaya daging dan tumbuhan (agriculture) yang dapat digunakan sebagai cadangan persediaan makanan dalam bangunan sekaligus menjadi objek studi atau penelitian. Pengunjung dapat bebas mengobservasi sampai kepada menyentuh tumbuhan, lebih bersifat eksperimental, sementara budidaya yang digunakan sebagai persediaan makanan diletakkan terpisah yaitu di dekat kantor pengelola karena untuk kebutuhan makanan diperlukan kondisi makanan yang lebih higenis bersamaan dengan kantor yang umumnya menjaga kebersihan dan kerapihan.

4. Cooking stage, panggung yang dapat digunakan untuk pertunjukkan atau kontes pembuatan makanan/minuman, apabila sedang tidak diadakan event tertentu dapat digunakan sebagai tempat membuat makanan seperti biasa.

Program transportasi berhubungan langsung dengan makanan seperti tempat duduk atau lesehan dapat digunakan untuk orang-orang nongkrong atau waktu beristirahat di tengah kesibukan kerja atau singgah selagi bertransportasi, juga dengan konsep seperti kios makanan di tengah stasiun kereta api. Pengunjung yang singgah tidak harus makan tetapi dapat juga memainkan permainan tertentu. 
Program anime/manga tidak sepenuhnya anime/manga untuk menghindari keeksklusifan; tersedia ruang workshop untuk melakukan aktivitas seputar anime/manga seperti menggambar, nonton, membuat busana cosplay, dan sejenisnya tetapi juga dapat digunakan oleh aktivitas serupa dengan objek pekerjaan selain anime/manga. Tersedia juga ruang serbaguna (multifunctional space) yang dapat digunakan oleh aktivitas apa saja yang umumnya publik atau membutuhkan ruang yang lebih besar seperti bazar, pertemuan tertentu, ataupun pameran.

Fasilitas pendukung lainnya adalah perpustakaan yang berisi buku-buku baik tentang Indonesia dan Jepang, juga buku-buku pengetahuan dan kebudayaan. Tidak hanya rak buku saja, di dalamnya juga tersedia tempat duduk lesehan sehingga fungsinya menjadi beragam tidak hanya duduk membaca saja tetapi dapat juga digunakan untuk belajar atau bermain sesuatu secara tiga dimensi seperti contohnya menyusun kerangka suatu objek. Perpustakaan dapat dikunjungi oleh semua jenis kalangan.

\section{Zoning}

Secara horizontal (denah) sisi timur tapak menjadi zona publik sementara sisi yang berlawanan lebih bersifat privat meskipun masih termasuk publik. Sisi tapak sebelah utara juga termasuk publik menjadi akses masuk utama ke dalam bangunan. Dimulai dari situlah lantai dasar diisi dengan program makanan seperti tempat makan bentuk bar dan group, cooking stage, galeri bahan makanan dan minuman, dan dapur publik. Pada bagian belakang mendekati sisi barat tapak diisi dengan indoor agriculture dan outdoor lounge. Program makanan diletakkan mulai dari lantai dasar karena merupakan program yang paling dominan dalam lingkungan tapak serta paling menjangkau banyak kalangan.

Kemudian masuk ke lantai 1 terisi kurang lebih sama seperti lantai dasar dengan perbedaan tersedianya tempat pengolahan daging, diletakkan di lantai atasnya agar lebih privat karena tidak semua orang suka dengan bau amis daging mentah. Lantai 1 lebih difokuskan kepada makanan untuk lunch atau dinner, sementara lantai dasar lebih kepada makanan dan minuman yang lebih ringan.

Kemudian ke lantai 2 sudah termasuk zona privat diisi dengan perpustakaan beserta kantor pengelola untuk perpustakaan tersebut. Terakhir lantai 3 yang diisi dengan kantor pengelola bangunan beserta outdoor agriculturenya untuk budidaya tumbuhan yang lebih dikhususkan untuk persediaan bahan makanan dalam bangunan. Workshop dan multifunctional space diletakkan juga di lantai 3 agar lebih mendukung secara struktur untuk membuat bentuk ruang dengan ceiling yang lebih tinggi dan bentang lebar. (lihat gambar 11)

\section{Gubahan massa}

Sebelum memulai proses gubahan massa dilakukan eksplorasi tatami (modul dasar 1:2) yang diputar ke sekian arah untuk mendapatkan angka-angka baru dengan maksud menggabungkan budaya tradisional Jepang (grid) dengan modern (bulat/lengkung) Angka-angka baru tersebut (warna merah) digunakan sebagai perhitungan dan dasar dalam membuat gubahan massa.

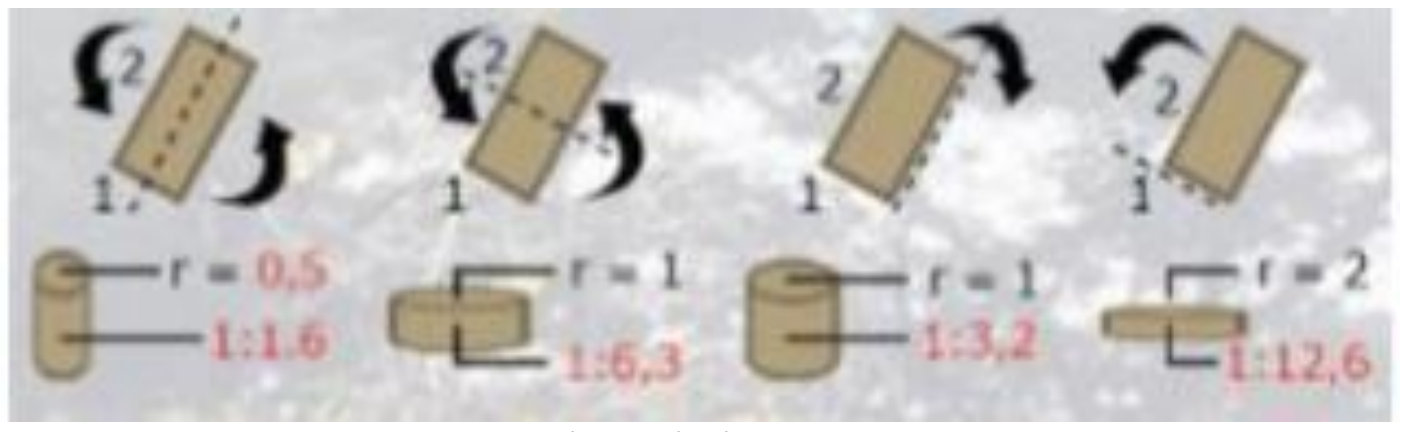

Gambar 8. Eksplorasi tatami

Sumber: Dokumentasi penulis, 2019 
Proses gubahan massa dilakukan dalam proses seperti berikut.

1. Gubahan massa dimulai dari kondisi fisik tapak berupa rerumputan yang terpangkas akibat sering dilalui motor untuk jalan pintas sehingga terbentuk suatu pola. Pola tersebut digunakan sebagai dasar untuk membentuk bangunan. Rumput yang terpangkas menggambarkan ruang yang bersifat publik seperti orang dapat berjalan-jalan di dalamnya, sementara rumput yang tidak terpangkas mengambarkan ruang yang bersifat lebih privat seperti ada kegiatan di dalamnyaMembuat pola garis dari pola rumput terpangkas. Langkah ini mengikuti prinsip memanfaatkan apa yang sudah ada.

2. Menyesuaikan ukuran pola garis dengan angka-angka rasio eksplorasi baru tatami. Eksplorasi baru tatami adalah mengambil unsur modul terkecil tatami (1:2) kemudian diputar dengan sekian cara sehingga menghasilkan rasio angka baru. Perputaran bentuk yang menghasilkan bentuk bulat adalah salah satu cara menggabungkan budaya tradisional dengan modern.

3. Memetakan titik-titik yang memungkinkan adanya pertemuan, percabangan, dan ruang privasi dengan simulasi semua ujung garis dimasukki oleh orang yang kemudian berjalanjalan di dalamnya. Setiap titik diberi penomoran; semakin banyak memungkinkan pertemuan/percabangan, semakin besar angkanya. (Gambar 9) Kemudian membuat lingkaran dengan ukuran jari-jari dari angka-angka baru eksplorasi tatami yang disesuaikan dengan penomoran tersebut, lingkaran-lingkaran tersebut kemudian dihubungkan per lantainya:

- Titik-titik privat menjadi dasar bentuk lantai teratas karena sifatnya privat

- Titik-titik cabang menjadi dasar lantai 1 merupakan kelanjutan dari lantai dasar

- Titik-titik temu menjadi dasar lantai 2.

- Gabungan semua titik-titik menjadi dasar lantai dasar karena sifatnya publik

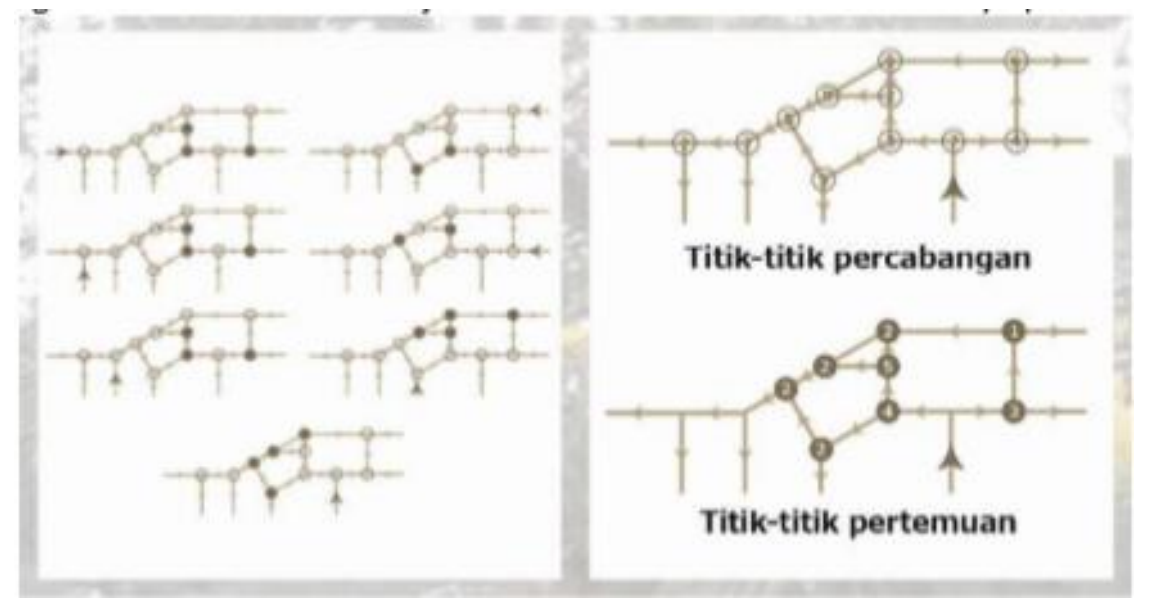

Gambar 9. Penjelasan langkah ke-3 gubahan massa Sumber: Dokumentasi penulis, 2019

4. Menghubungkan seluruh dasar lantai secara vertikal sehingga terbentuk 1 massa.

5. Melakukan permainan bentuk massa dengan melebarkannya ke samping (untuk teras dan drop off) dan ke atas sesuai kebutuhan ruang di dalamnya.

6. Penyempurnaan: menambahkan pola kotak-kotak (kaca dan kusen aluminium) pada fasad dan penutup atap zinkalum sehingga menghasilkan bangunan dengan bentuk seperti pada gambar 10 berikut. 


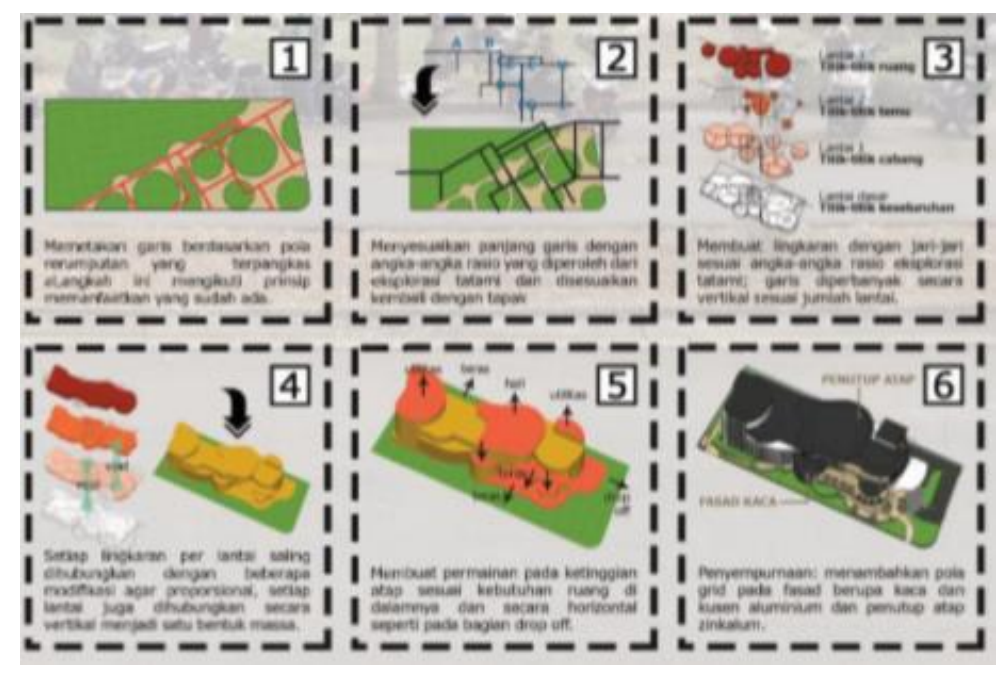

Gambar 10. Proses gubahan massa

Sumber: Dokumentasi penulis, 2019

\section{Hasil perancangan}

\section{a. Akses bangunan}

Akses masuk dan keluar bangunan terletak di sisi utara tapak terbagi menjadi dua: sebelah barat daya untuk kendaraan bermotor, sebelah timur laut untuk pejalan kaki. Akses kendaraan bermotor terletak di sebelah utara dengan tujuan agar kendaraan yang datang dari utara di jalan BSD Raya Utama dapat langsung berbelok kanan di perempatan dekat tapak kemudian langsung masuk ke dalam bangunan sehingga akses lebih mudah. Akses pejalan kaki terletak di sebelah timur laut merupakan penyambungan dengan akses masuk AEON mall dan juga menjadi titik tengah bertemunya para pengunjung yang datang dari berbagai arah.

\section{b. Sirkulasi ruang}

Ketika kendaraan bermotor memasuki bangunan, terdapat dua cabang utama yaitu untuk menuju drop off dan menuju parkir motor; parkir motor langsung diarahkan ke akses keluar. Setelah drop off terdapat dua cabang lagi, untuk keluar bangunan dan menuju ramp ke parkir motor lantai basement (dua arah). Apabila mobil yang setelah parkir ingin kembali untuk menjemput orang tidak perlu kembali ke drop off karena pada lantai basement juga tersedia tempat drop off kecil.

Untuk pengunjung (pejalan kaki), dari akses masuk pejalan kaki langsung disambut dengan tempat-tempat duduk yang dapat berhubungan langsung dengan drop off. Pengunjung juga dapat memarkirkan sepedanya di situ. Kemudian memasuki pintu utama ke resepsionis dan main hall, ruang informasi. Pengunjung kemudian memasuki food court beserta tempat makan bentuk bar dan dapur publik, juga terdapat lesehan tatami. Selanjutnya terdapat cooking stage dan galeri bahan makanan beserta indoor agriculture. Di dekat cooking stage terdapat ramp spilar untuk naik ke lantai 1.

Layout lantai 1 kurang lebih sama seperti lantai dasar, hanya ruang persis di atas indoor agriculture diganti dengan ruang pengolahan daging. Terdapat juga teras bagian belakang untuk outdoor agriculture tipikal sampai lantai 3. Kemudian pengunjung berjalan dari ramp menuju ruang yang dekat dengan akses masuk bangunan pejalan kaki, di atasnya pintu utama, terdapat ramp melingkar lagi untuk naik ke lantai 2 menuju perpustakaan. Pada bagian belakang perpustakaan terdapat kantor pengelola perpustakaan yang terhubung dengan outdoor agriculture lantai 2.

Lantai 3 diakses dengan tangga atau lift berisi multifunctional space dan workshop, beserta kantor pengelola bangunan yang juga terhubung dengan outdoor agriculture. Lantai berikutnya di atas lantai 3 adalah lantai untuk servis seperti ruang mesin lift, mesin AC, dan roof tank. Lantai basement berisi parkir mobil beserta akses menuju lantai dasar, loading dock, ruang servis air, ruang servis listrik, dan ruang servis sampah. 
Pengunjung tidak harus mengikuti alur yang telah dijelaskan sebelumnya ketika mengunjungi bangunan ini. Lift dan tangga yang terhubung ke semua lantai menjadi kebebasan bagi pengunjung apabila ingin mengunjungi bangunan dengan alur yang berbeda atau tidak sedang ingin mengunjungi semua ruang bangunan.

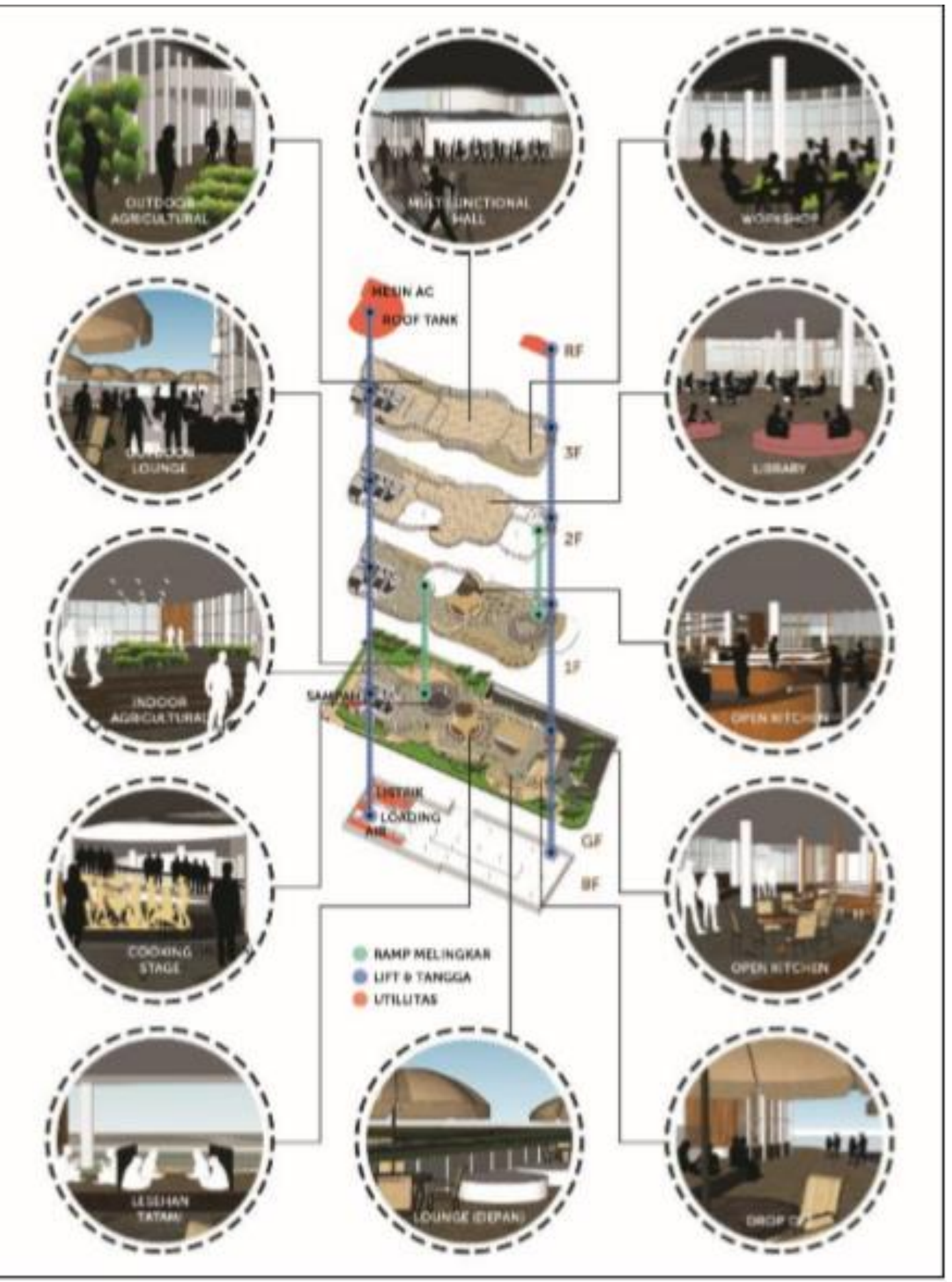

Gambar 11. Organisasi ruang bangunan

Sumber: Dokumentasi penulis, 2019 

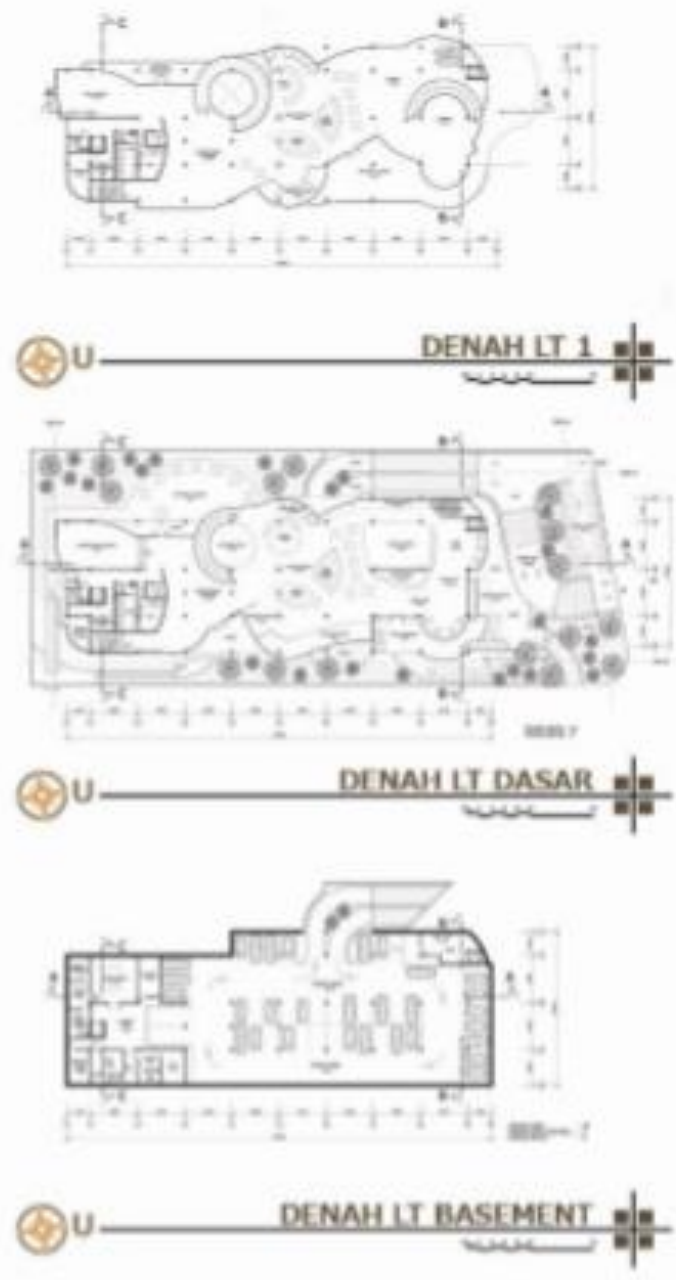
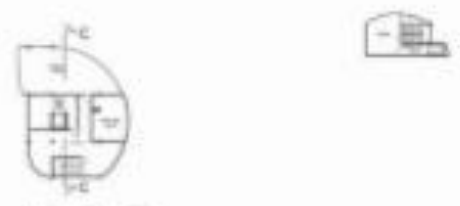
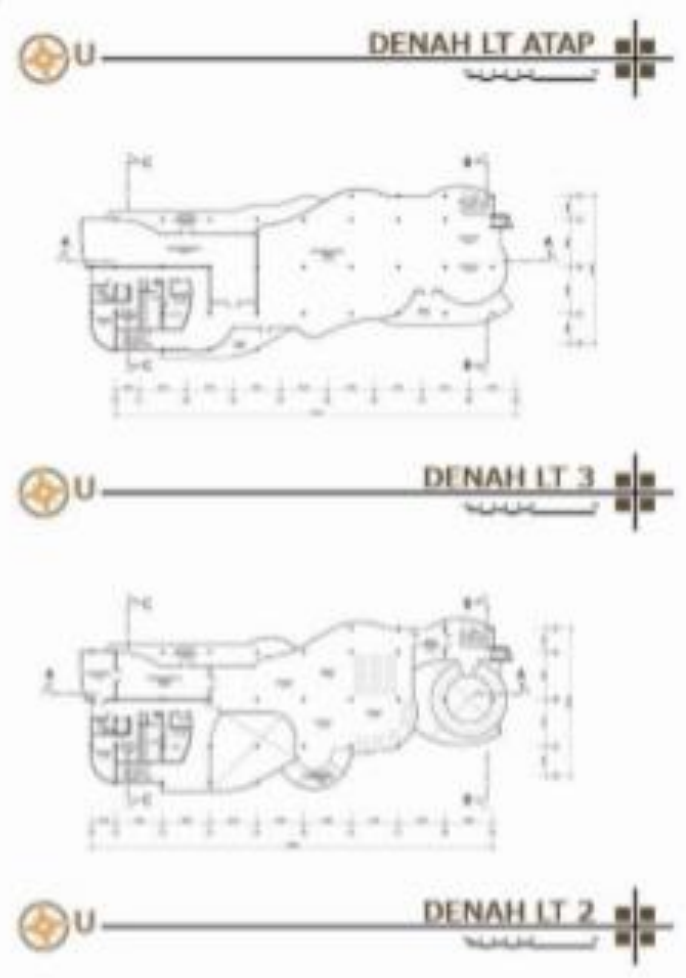

Gambar 12. Denah seluruh lantai bangunan

Sumber: Dokumentasi penulis, 2019

c. Penampilan fisik bangunan

Fasad bangunan hampir seluruhnya menggunakan kaca dengan kusen aluminium berpola grid yang mencerminkan karakter Jepang tetapi juga sekaligus menjadi karakter bentuk modern agar tidak terkesan tertinggal zaman. Bangunan juga dilengkapi landscape dengan tumbuhan hijau sehingga tetap bersifat dekat dengan alam.

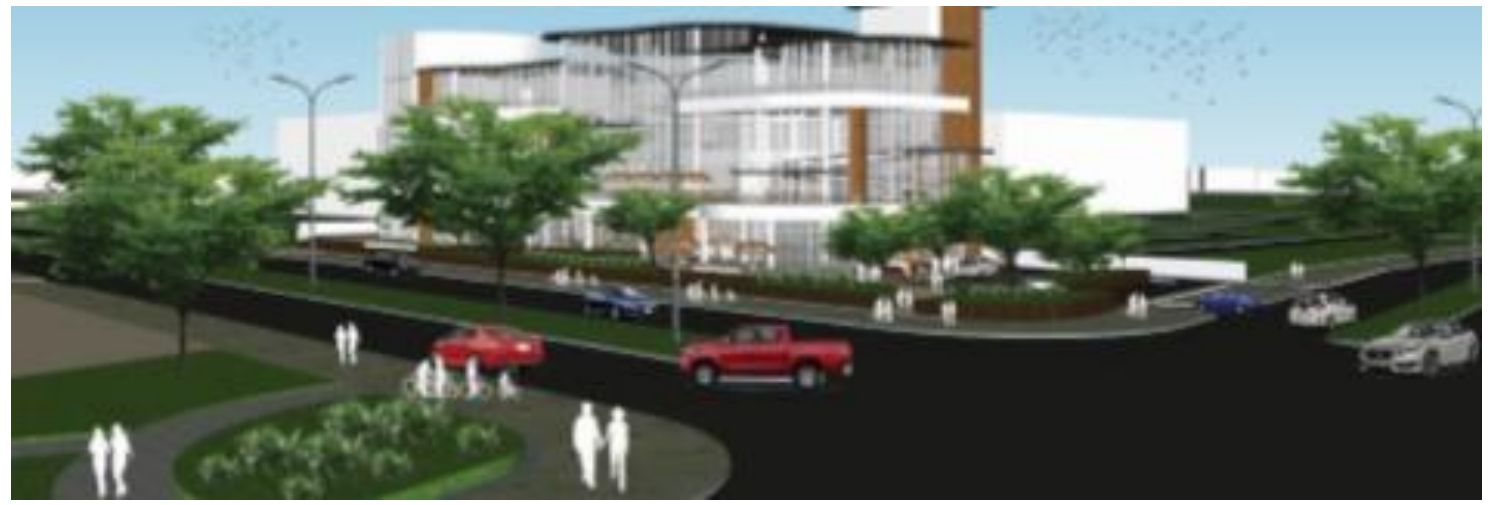

Gambar 13. Tampak muka bangunan

Sumber: Dokumentasi penulis, 2019 


\section{KESIMPULAN DAN SARAN}

Indonesia menerima budaya luar sekaligus mempertahankan budaya lokal dengan menggunakan material dan wujud fisik Jepang (material tatami, pola grid fasad) tetapi dengan karakter (nilai dan penggunaan) lokal Indonesia. Produk Jepang tidak benar-benar eksklusif tetapi juga bersahabat dengan kebudayaan Indonesia. Keterkaitan rancangan proyek dengan third place adalah:

a. Netral; program hybrid seperti material berkarakter Jepang tetapi dengan nilai budaya lokal seperti pada program makanan, perpustakaan, multifunctional space, dan workshop yang multifungsi.

b. Leveller; program makanan lantai dasar yang dapat melakukan kegiatan makanan dan minuman secara bebas.

c. Conversation; layout tempat duduk group seperti pada foodcourt dan lesehan tatami yang memungkinkan interaksi antar pengunjung, dan bar yang memungkinkan interaksi antara pengunjung dengan pelayan

d. Aksesibilitas dan akomodasi; lokasi perancangan dekat dengan hunian seperti BRANZ BSD, kost sekitar Universitas Prasetya Mulya, dan perumahan BSD lainnya. Meskipun berjarak lebih dari satu $\mathrm{km}$ dari tapak, jalur mobil terfasilitasi dengan baik di mana pengunjungnya juga masih banyak yang menggunakan mobil dan motor sehingga tergolong mudah.

e. Identitas lokal; kebudayaan Indonesia dan Jepang yang diasimilasikan.

f. Low profile; tidak ada kepura-puraan, pengunjung boleh berkreasi sekreatif mungkin.

g. Playful; dapur publik, ruang workshop, dan perpustakaan dengan tempat duduk lesehan yang memungkinkan munculnya kegiatan-kegiatan kreatif.

h. A home far away from home : dapat digunakan untuk melakukan kegiatan hobi seperti membuat makanan, menggambar, membuat busana, dan lainnya.

Dalam perancangan third place, karakteristik sebuah lokasi adalah unsur terpenting untuk mulainya sebuah perancangan terutama budaya apa saja yang dimiliki oleh lokasi tersebut, atau dapat juga dimulai dari isu yang sangat global.

\section{REFERENSI}

Davies, R. (2002). The Japanese Mind: Understanding Contemporary Japanese Culture. Singapore: Berkeley Books.

Kim, K. (2016). Cultural Hybridity in the Contemporary Korean Popular Culture through The Practice of Genre Transformation. Tesis. The University of Western Ontario. London.

Kistanto, N. H. (2015). Tentang Konsep Kebudayaan. Sabda: Jurnal Kajian Kebudayaan, 10(2).

Kurniawan, J. (2009). Analisis Makna Konotatif yang Berhubungan dengan Konsep Wabisabi dalam Tiga Buah Haiku Karya Matsuo Basho. Skripsi. Program S1 Sastra Jepang Binus University. Jakarta.

Kurokawa, K. (1994). The Philosophy of Symbiosis.

Oldenburg, R. (1997). The Great Good Place. Boston: Da Capo Press.

Priyambodo, B. (2015). Eksistensi Lokalitas dalam Perancangan Hotel Resor Tanjung Aan. Jurnal Sains dan Seni ITS, 4(2), 39-42.

Sharr, A. (2007). Heidegger for Architects. Abingdon: Routledge.

Supply Chain Indonesia. (2019). Kumpulan Data Ekspor Impor Indonesia. Retrieved January 27, 2020, from http://supplychainindonesia.com/new/wpcontent/files/SCl_Data_Ekspor_Impor_Indonesia_Edisi_Juni_2019.pdf 
